\title{
Caryologia
}

International Journal of Cytology, Cytosystematics and Cytogenetics

\section{Analysis of Mitosis in the Presence of RNA Synthesis Inhibitors in Meristematic Cells}

\section{C. Risueño \& S. Moreno Diaz De La Espina}

To cite this article: M. C. Risueño \& S. Moreno Diaz De La Espina (1978) Analysis of Mitosis in the Presence of RNA Synthesis Inhibitors in Meristematic Cells, Caryologia, 31:1, 43-61, DOI: 10.1080/00087114.1978.10796729

To link to this article: https://doi.org/10.1080/00087114.1978.10796729

曲 Published online: 30 Jan 2014.

Submit your article to this journal $\sqsubset$

山 Article views: 49

Q View related articles $\widetilde{ }$ 


\title{
ANALYSIS OF MITOSIS IN THE PRESENCE OF RNA SYNTHESIS INHIBITORS IN MERISTEMATIC CELLS
}

\author{
M. C. RISUEÑO and S. MORENO DIAZ DE LA ESPINA \\ Departamento de Citologia, Instituto de Biologia Celular, Madrid, Spain
}

Received: $2^{\text {nd }}$ November 1976

\section{INTRODUCTION}

Some authors have noted the effect of the inhibition of RNA synthesis on the evolution of mitosis (GIMENEZ-Martin et al. 1971; GonzALEZ-FERNANDEZ et al. 1970). The effect of RNA synthesis inhibition on cells initiating mitosis was described as a blocking of their division cycle in prophase. Blocking the nuclear envelope breakdown prevents the cells from reaching metaphase (GonZALEZ-FERnANDEZ et al. 1970). But later studies under the electron microscope allowed us to ascertain that the chromosomic cycle went on (RIsUeño et al. 1975).

In this study we shall describe at the ultrastructural level the action of continuous treatment with two antimetabolites which affect RNA synthesis: cordycepin (3'AdR) and ethidium bromide (EB), on the evolution of mitosis, in meristematic cells of Allium cepa that begin prophase in the presence of these drugs.

The modifications observed in the mitosis of treated cells will be analyzed in relation to the nucleolar and chromosomal cycles of untreated mitotic cells.

The different steps in the evolution of these cells were previously identified under the optical microscope by means of semithin sections.

\section{MATERIAL AND METHODS}

The material used was root meristem of Allium cepa L. The onion bulbs were grown in the dark at a constant temperature of $15^{\circ} \pm 0.5$, in tap water which was renewed every $24 \mathrm{hr}$. and aerated continuously by bubbling air at $10-20 \mathrm{ml} \mathrm{min}^{-1}$.

[Caryologia, Vol. 31, n. 1, 1978 


\section{Treatments.}

The roots, still attached to the bulbs were transferred to the drugs under the some conditions as were used for growing. Roots were fixed 1, 3, 6 and $12 \mathrm{hr}$ after beginning of the treatment.

The drugs were used at the following concentrations: EB $\left(100 \mu \mathrm{gr} . \mathrm{ml}^{-1}\right)$ and 3'AdR $\left(10^{-4} \mathrm{M}\right)$.

Roots were fixed in $3 \%$ glutaraldehyde for $2 \mathrm{hr}$ at room temperature in either $0.025 \mathrm{M}$ Palade's or cacodylate buffer at $\mathrm{pH}$ 6.9. Roots were postfixed in $1 \%$ osmium tetroxide in the same buffer for $1 \mathrm{hr}$ at room temperature.

They were dehydrated in alcohol series and embedded in Epon 812 .

Sections were stained with $1 \%$ uranyl acetate in absolute alcohol for $30 \mathrm{~min}$. at room temperature and poststained with lead citrate according Venable and GogeshaLl (1965).

Different mitotic stages were localized by using $2 \mu \mathrm{m}$ thick sections, stained with $0.5 \%$ toluidine blue in $1 \%$ borate buffer for $0.5 \mathrm{~min}$., washed in distilled water and observed under the light microscope.

\section{RESULTS}

I. Cells under the effect of EB.

a) Nuclear envelope.

The nuclear envelope remains fully visible during prophase and metaphase (Figs. 13, 14).

In anaphase, when the chromosomal movement begins, the nuclear envelope closes up against the crhomosomes and suffers ruptures at some

Figs. 1 to 12.

EB 6 h. Ligth microscope photographs. Glutaraldehyde-Osmium fixation, stained with toluidine blue. $x 1.200$. The scale corresponding to $10 \mu \mathrm{m}$.

Fig. 1. - $a$ and $b$ ) interphase cells chromatin with its typical pattern, the nucleolus (arrows) is degranulated by the action of the inhibitor (RIsUEÑo et al. 1972) and shows a clear area which correspond to the space occupied by the nucleolar components before their dispersion. c) Early prophase, stage by corresponding to Fig. 13. The chromatin is in clearly distinguishable form from those in Fig. $a$ and $b$. Nucleolus (arrow) at the beginning of its dispersion.

Fig. 2. - A more advanced prophase than in Fig. 1c. The chromatin condensation is more advanced and the nucleoli (arrows) are more dispersed than in Fig. 1c. Clear areas around the nucleolus (points) corresponding to the space occupied by it before its dispersion which is not occupied by the chromosomes.

Fig. 3, - Prometaphase stage corresponding to Fig. 14. The nucleolus has disappeared and only a small remnant (arrow) of it is visible inside the clear area. The chromosomes are apposed to the nuclear envelope.

Figs. 4 and $5 \mathrm{a}$. - Cells in stages analogous to the metaphase in normal mitosis. The condensed chromosomes still inside the nuclear envelope, without moving to the metaphase plate.

Fig. 5b. - Sister cells in advanced interphase. The cell plate has strangulated the nucleus in two parts.

Figs. 6 and 7. - Early anaphases corresponding to Fig. 15. The movement of the chromosomes towards the poles has begun, but the nucleolar material is not yet liberated by the chromosomes. 

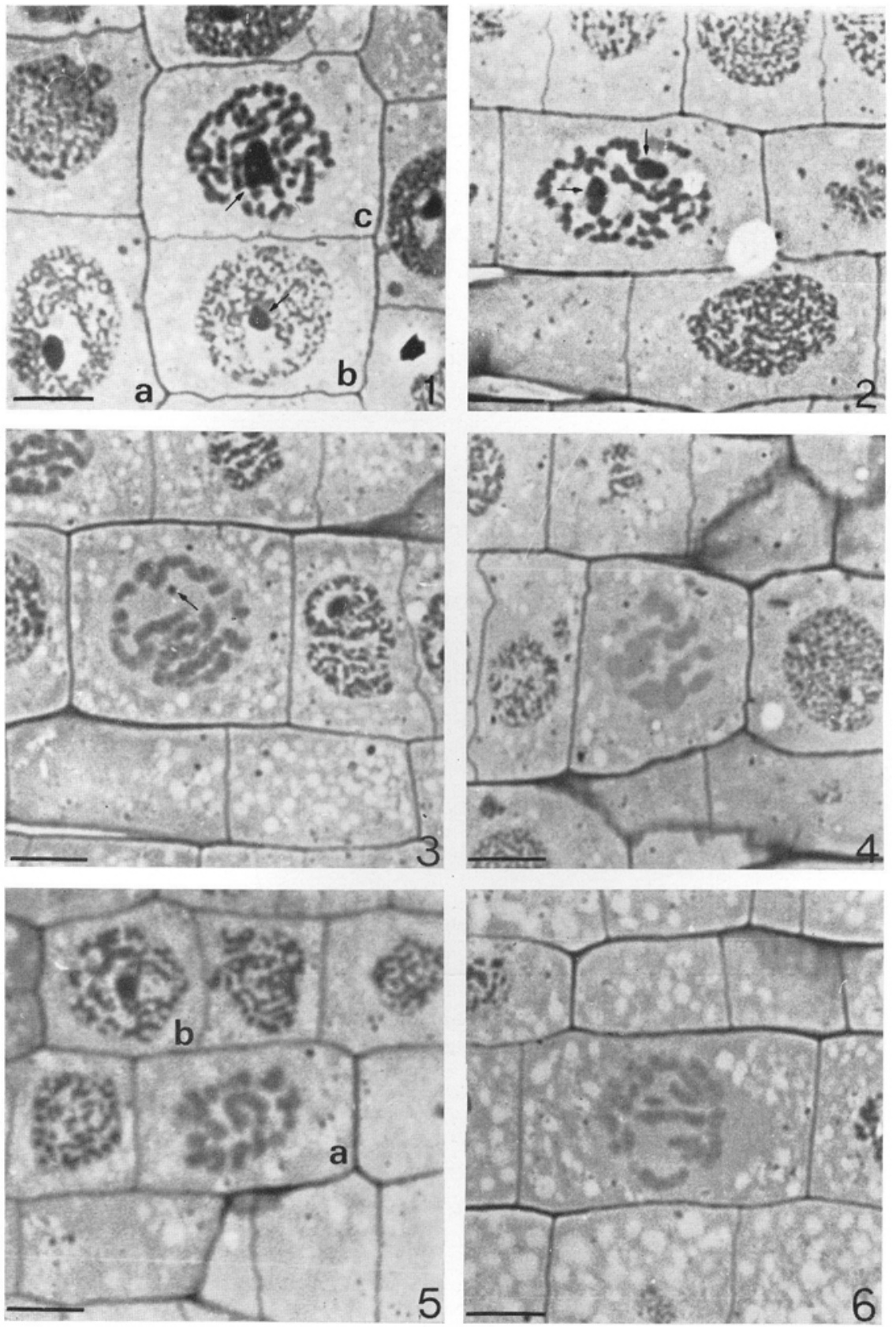
chromatin-free sites. This discontinuity of the nuclear envelope is clearly observed in potassium permanganate fixations. Through these breaks penetrate the microtubules, making contact with the chromosomes (Fig. 15).

In telophase the nuclear envelope, which has remained apposed to the chromosomes, reconstitutes, in those places where it had broken. The new pieces are formed apposed to the chromosomes so that, in some cases, nucleolar material is left outside the nucleus (Fig. 18).

In interphase, the nuclear envelope shows a certain lobulation (Fig. 21) due to the effect of EB (DE LA TORRE et al. 1973).

\section{b) Evolution of the chromatin.}

An analysis of the chromosomal evolution of cells treated with EB show progressive chromatin condensation as the cells pass from interphase to prophase (Fig. 1). In mid-prophase the chromosomes are individualized and show the degree of condensation characteristic of this stage. The nuclear envelope is clearly visible and the nucleolus shows already the structure corresponding to its dispersion in prophase (Fig. 13) (Moreno Diaz De LA EsPINA et al. 1974, 1976; RisUEÑo et al. 1976).

As mitosis goes on, the chromosomes becomes more and more condensed (Fig. 2). The nucleolus, as an organized structure had disappeared and only a few remnants of it are seen adjacent to the chromosomes. The chromosomes begin to line up parallel to the nuclear envelope (Fig. 3) to which they are adjacent by metaphase (Figs. 4, 5, 14) showing the condensation typical of untreated cells. We must point out that the chromosomes are straight unlike those treated with 3'AdR. In central sections of the nucleus, a chromosome-free zone may be seen in the nucleoplasm (Figs. 3, 14) this is the zone occupied by the nucleolus before its dispersion.

Another phenomenon observed in these cells is the great number of

Fig. 8. - Stage corresponding to a late anaphase or very early telophase. The chromosomes have started their decondensation process and consequently the nucleolar material (arrows) begins to appear in their periphery.

Fig. 9. - Telophase. More advanced chromatin decondensation than in Fig. 8. Nucleolar material in the cytoplasm (arrow) left outside of the nucleus when the nuclear envelope reconstitutes (see Fig. 18).

Fig. 10. - Advanced telophase analogous to Fig. 17. Chromatin more decondensed than in Fig. 9. Cell plate in formation in both sides of the cell (arrows).

Fig. 11. - Very early interphase analogous to Fig. 19. The chromatin is not totally decondensed. The cell plate strangulates the nucleus at several points. Prenucleolar bodies in the interchromatin spaces (arrows).

Fig. 12. - a) Medium interphase analogous to Fig. 20. The chromatin decondensation is more advanced than in Fig. 11. Prenucleolar bodies in the interchromatin spaces. Cell plate strangulating the nucleus. b) sister cells in advanced interphase, analogous to Fig. 21, with a more decondensed chromatin, a complete cell plate and prenucleolar bodies in the interchromatin spaces. Fig. 1-12. x 1.200 . 

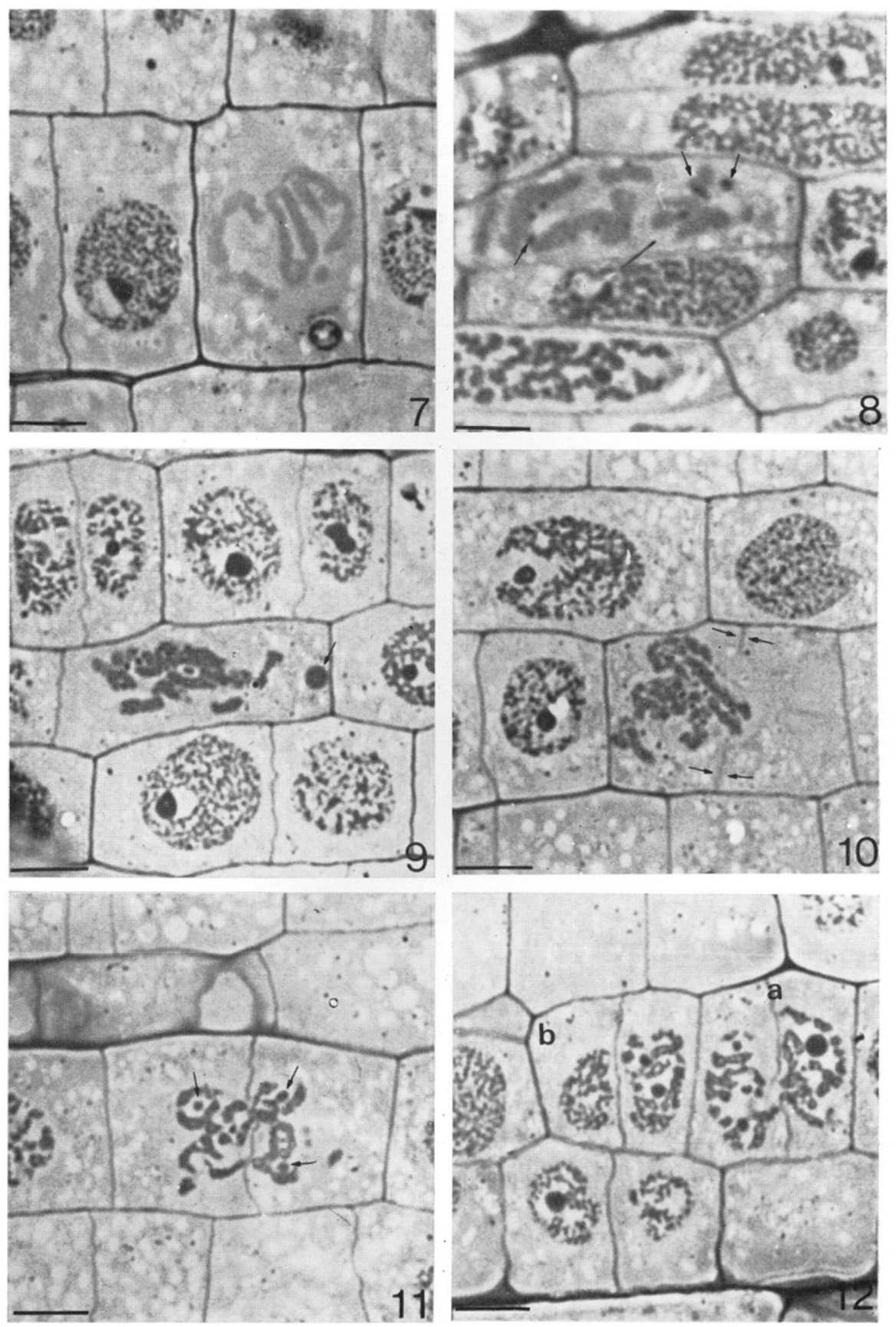
connections between the chromosomes themselves and between the chromosomes and the nuclear envelope (Figs. 14, 16). These short, dense connections consist of chromatin fibres and their thickness varies according to the plane of the section.

During anaphase (Figs. 6, 7, 15) there is a chromosomal movement towards the outside of the nucleus and towards the poles. This movement could be due to two different causes: 1) the free movement of the cromosomes or 2) there may be a dragging action by the microtubules associated to the kinetochores.

These microtubules penetrate into the nucleus in zones where the nuclear envelope has broken and are not those same interzonal microtubules involved in cell plate formation during telophase (Fig. 19).

In telophase, progressive chromosome decondensation is observed (Figs. 8, 9, 10, 17), which causes the emigration of nucleolar material into the interchromatin spaces, thus giving rise to the formation of the prenucleolar bodies (Moreno Draz De La Espina et al. 1976; Risueño et al. 1976).

In this phase, cell plate formation takes place on both sides of the nucleus. Interzonal microtubules (Fig. 19) can be observed associated with the small vesicles (RISUEÑo et al. 1971). The plate continues to grow producing strangulation of the nucleus into two unequal parts (Figs. 10, $11,12,20,21)$.

Chromatin decondensation progresses, reaching its characteristic interphase configuration (Fig. 21). In the interchromatin spaces the prenucleolar bodies, which have not fused to form the nucleolus, persist (Figs. 12, 21).

\section{c) Microtubules.}

As mentioned before, in cells going through prophase in the presence of EB, no mitotic spindle is formed, although centromere fibres exist making contact with the chromosomes through the ruptures in the nuclear envelope, giving rise to their emigration (Fig. 15).

The interzonal microtubules, which take part in cell plate formation, are perfectly functional in these cells (Fig. 19).

Figs. 13 to 26. - Electron microscope. Glutaraldehyde-Osmium fixation, stained with uranyl acetate and lead citrate. The scale corresponding to $1 \mu \mathrm{m}$ except for Fig. 16.

Fig. 13. - EB 3 h. Prophase. The nuclear envelope is patent, and the chromosomes show connections with it (arrows). Nucleolus in dispersion (nu). $\times 17.600$.

Fig. 14 - EB 6 h. Metaphase. The nuclear envelope remains (ne). The chromosomes are more condensed and apposed to the nuclear envelope. They show connections between themselves and the nuclear envelope (arrows). Clear area in the nucleoplasm corresponding to the space occupated by the nucleolus before its dispersion $(\star) . \times 9.690$. 


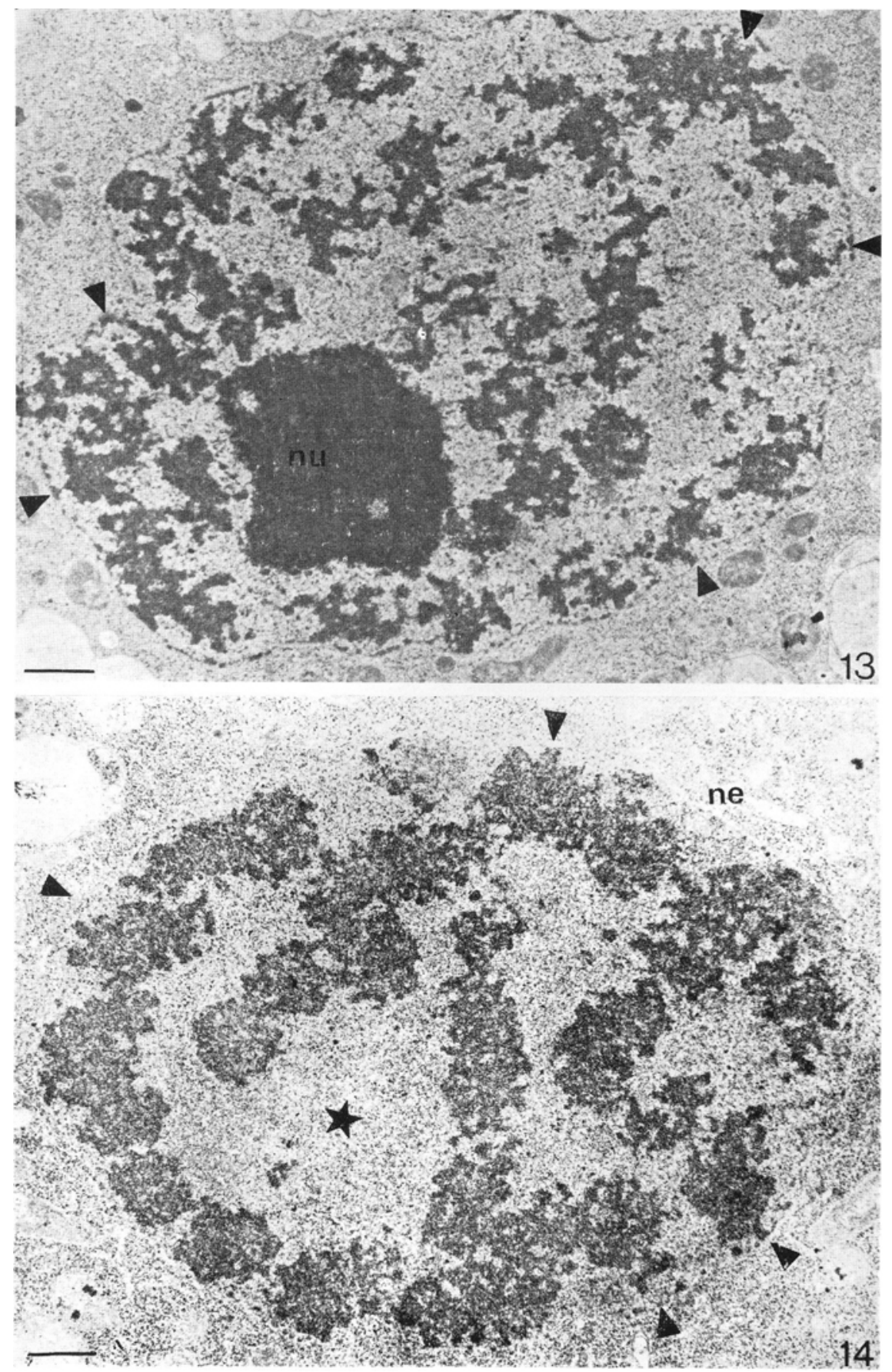




\section{Cells under the effect of cordycepin.}

\section{a) Chromatin.}

The effect of cordycepin on meristematic cells of Allium cepa, in contrast with those produced by ethidium bromide, is observed from the first hours of treatment in the form of intense chromosome condensation followed by retraction. Finally, the chromosomes acquire an U-shape.

At the beginning of prophase the chromatin condenses giving rise to the individualization of the chromosomes.

In late prophase, the chromosomes' condensation is more advanced than the nucleolar dispersion besides control cells (Fig. 22). The nucleolus shows the same alterations as in interphase (Gimenez Martin et al. 1973).

In prometaphase, there is an intense condensation of the chromosomes, which begin to take on a U-shape (Fig. 24). The nucleolus has lost its organized structure and the nuclear envelope appears well preserved around the nucleus. Like EB, cordycepin induced the formation of connections between the nuclear envelope and the chromosomes and between the chromosomes themselves (Figs. 23, 24).

In metaphase, the chromosomes, show both a high electron density and an intense condensation, and adopt a bow shape (Fig. 25). At greater magnification metaphase chromosomes clearly show both chromatids and the centromere region (arrow, Fig. 25). Chromosomal interconnections (chromosomal stickness) consisting of chromatin strands are plainly visible.

The chromosomes later move near the nuclear envelope, leaving the bigest part of the nucleoplasm free. That is probably due to the free movement of the chromosomes; which are kept back by the elastic nuclear envelope. The chromosomic contraction reaches its highest degree in this phase (Fig. 26) and is greater than that observed in untreated cells. Chromosome length in cells treated with cordycepin is notably shorter than in cells treated with EB. The chromosomes and the connections between them are very dense to the electrons. The nuclear envelope is clearly visible throughout this phase (Fig. 25).

Unlike $\mathrm{EB}$, cordycepin treatment prevents ulterior decondensation of the chromosomes.

Fig. 15. - EB $6 \mathrm{~h}$. Anaphase. Chromosomal shift towards the poles. The nuclear envelope remains in some zones apposed to the chromosomes (arrows head). Microtubules within the nucleus are associated with the kinetochores (big arrows). $\mathrm{x} 10.800$.

Fig. 16. - EB $6 \mathrm{~h}$. Connections between the chromosomes themselves (arrows) and with the nuclear envelope (big arrows) are clearly visible from metaphase on. $x 13.965$. Scale $0.5 \mu \mathrm{m}$. Fig. 17. - EB $6 \mathrm{~h}$. Telophase. Chromosomes in decondensation with the nuclear envelope apposed to them. Nucleolar material $(\mathrm{nm})$ cell plate $(\mathrm{cp})$ in formation with interzonal microtubules (arrows) $\times 10.077$. 


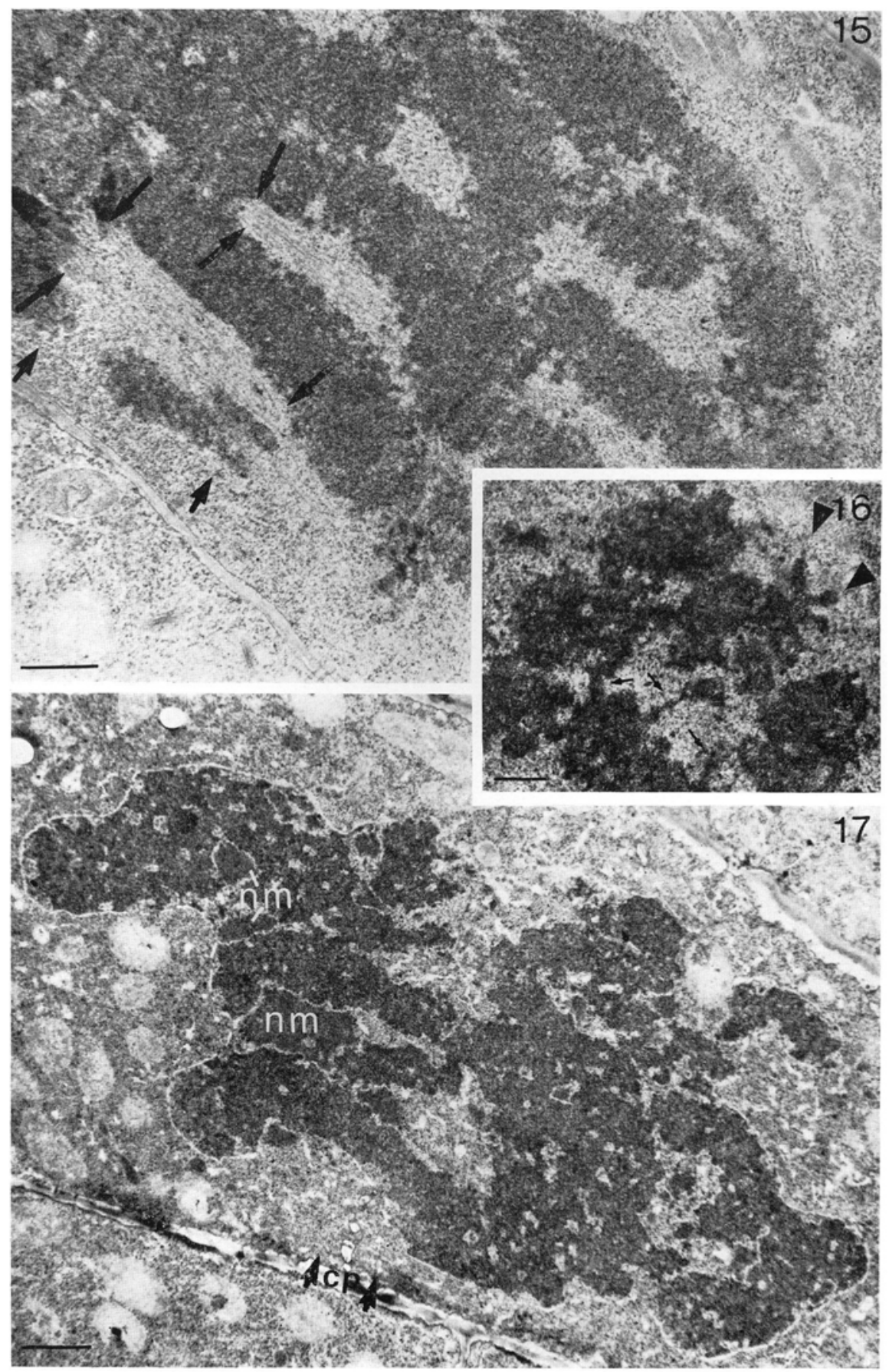


b) Nuclear envelope.

The nuclear envelope remains intact until the stage at which the chromosomes reach maximum condensation (Figs. 22 to 26). In no case ruptures or the passage of microtubules through the nuclear envelope are seen. In some cases it has a lobular appearance, possibly due to the movement of the chromosomes.

\section{c) Microtubules.}

No mitotic spindle is formed in these cells, neither do interzonal microtubules appear. In prophase, the prophase ring of microtubules is seen around the nuclear envelope (Fig. 23), later they disappear, so that by the stage of maximum chromosome condensation they are no longe seen.

\section{DISCUSSION}

\section{a) Chromatin.}

The above observations point to a certain similarity between progressive changes of the chromosomes in treated cells and the phenomenon of endomitosis (GIMENEz MARTIN et. al. 1971) which is characterized by the absence of spindle formation, the absence of chromatid separation and an increase of cellular ploidy (BIER 1957; GEITLER 1953; NAGL 1972; Nur 1968). Nevertheless, none of the phenomena studied here may be considered a complete endomitotic process, since, with cordycepin the cells do not appear to advanced beyond endometaphase or endonaphase, and $\mathrm{EB}$ causes the nucleus to divide into two and thus induces an unequal distribution of the chromosomes.

In addition there are in this case two phenomena which are not found in endomitosis: the highly intense chromosomal condensation in the case of 3'AdR treatment and the chromosomal stickiness in both 3'AdR and EB treatments. The chromosomal contraction could be compared to that described in endomitosis in insects (TsCHERMAK-WoEss 1971) but not to that in Angiosperms, because in this case, there is practically no chromosomal condensation and endomitosis is considered as an interruption of the cell cycle during early prophase (D'Amato 1964; NAGL 1972).

Some authors (IKeuchi et al. 1971; Matsur et al. 1971; RAo and

Fig. 18. - EB $6 \mathrm{~h}$. Telophase. The nuclear envelope reconstitutes apposed to the chromosomes (arrows) and the nucleolar material is left in some cases outside the nucleus (pb). Microtubules (thin arrows) are clearly visible at this stage. x 27.700 .

Fig. 19. - EB $12 \mathrm{~h}$. Early interphase. Cell plate in formation (arrows) with vesicles and interzonal microtubules. Chromatin (chr) prenucleolar bodies (pb) in the nucleus. $x$ 24.620. 

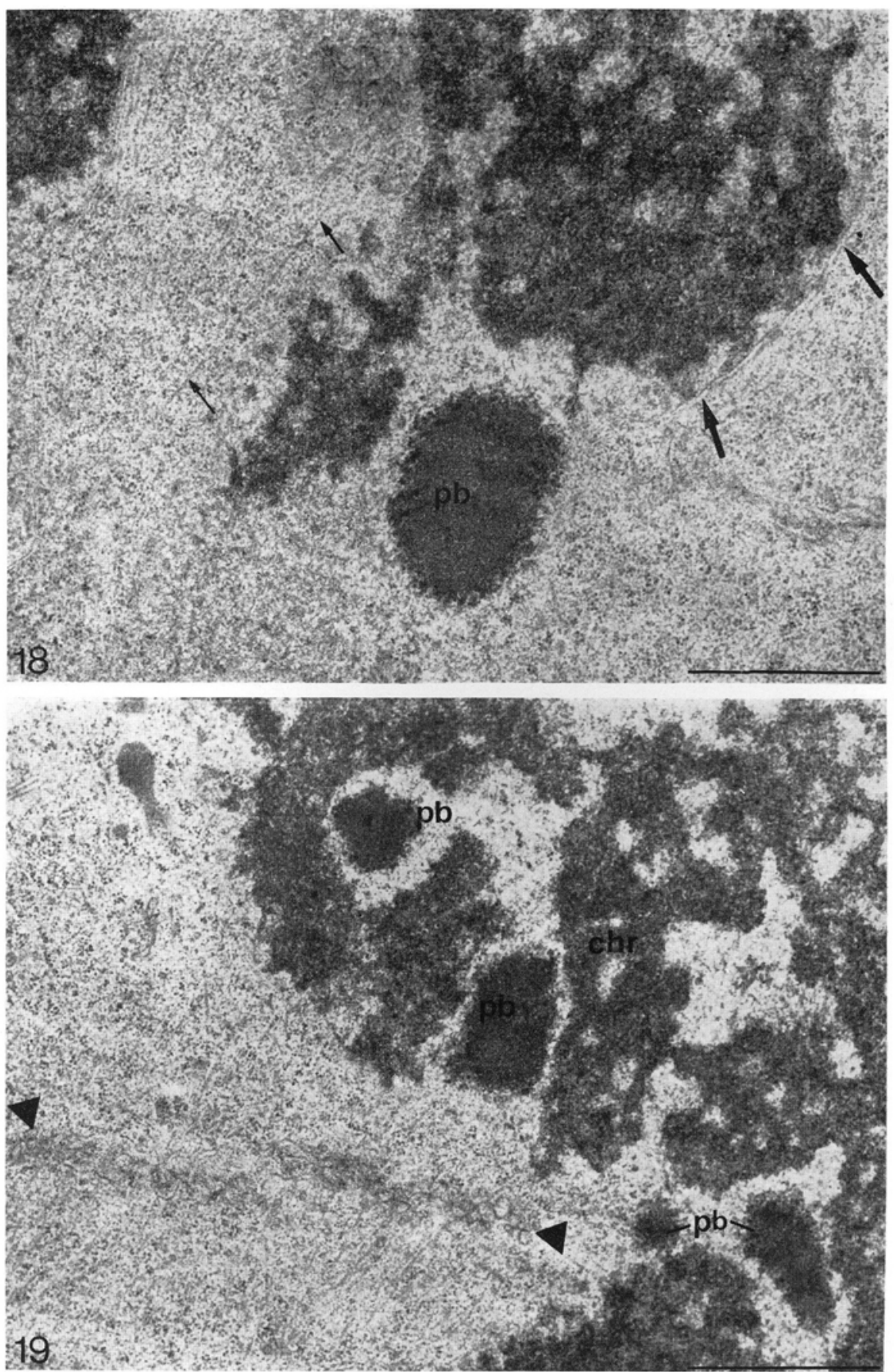
JoHnson 1970) have suggested that chromosome condensation is stimulated by a substance, probably a protein, which provokes premature condensation of the interphase nucleus, and which is sinthesized during the $G_{1}$ period. Cordycepin is, a powerful transcription inhibitor, which affects the formation of polyadenylic acid (Harris and Dure 1974; PENMAN et al. 1970), which, as we know, codes the end of the message. In this way the pool of the protein responsible for condensation would be affected. The presence of the drug would produce a larger quantity of the protein than it is physiologically normal, thus provoking intense chromosomal condensation and the blockage of the chromosomal decondensation. This hypothesis is also in agreement with the results obtained with anisomycin treatment, where chromatin condensation is halted in prophase, which regresses to interphase (GARCIAHERDUGo et al. 1974) suggesting the necessity of a protein for chromosomal condensation (unpublished data).

Ethidium bromide, on the other hand, does not produce this intense chromosomal condensation. This drug intercalates itself between specific base pairs of the molecule thus lengthening the chain (WARING 1965), and modifies the structural configuration of DNA, giving rise to a conformation with turns to the left (CRAWFORD and WARING 1967). This would cause great rigidity in the chromosomes and would explain firstly the chromosomefree zone in the nucleoplasm corresponding to the nucleolus, secondly the fact that U-shaped chromosomes are not found, and finally the absence of the intense chromosomal contraction characteristic of cordycepin.

As to the phenomenon of chromosomal stickness, so amply described in classical cytology (BEADLE 1932; LINDEGREN 1961) in our case the recent interpretation offered by Mc GILL et al. (1974) and PATHAK et al. (1975) seems valid. They account for it as the failure of preprophase chromatin to condense, since the fibres are trapped in a tangle with fibres of other chromosomes. In our case these connections are short and do not relate to the chromosomal bridges, since the nuclear envelope does not break and there is no normal chromosomal migration. A similar interpretation would be valid for the connections between the chromosomes and the nuclear envelope.

Fig. 20. - EB 12 h. Medium interphase. The chromatin (chr) decondensation is not yet completed. The whole nuclear envelope is formed at this stage. Cell plate in formation (c.p.) with associated interzonal microtubules (arrows). Prenucleolar bodies in the interchromatin spaces $(\mathrm{pb}) . \times 12.600$.

Fig. 21. - EB $12 \mathrm{~h}$. Late interphase. The chromatin has its characteristic interphase configuration. The cell plate (c.p.) is formed. Prenucleolar bodies persist in the interchromatin spaces. $\mathrm{x} 5.745$.

Fig. 22. - 3' AdR 6 h. Phophase. The nucleolus (nu) shows the same alterations as in interphase, under the effects of the drug; its disperssion is delayed with respect to the chromosomes condensation. $\times 6.064$. 

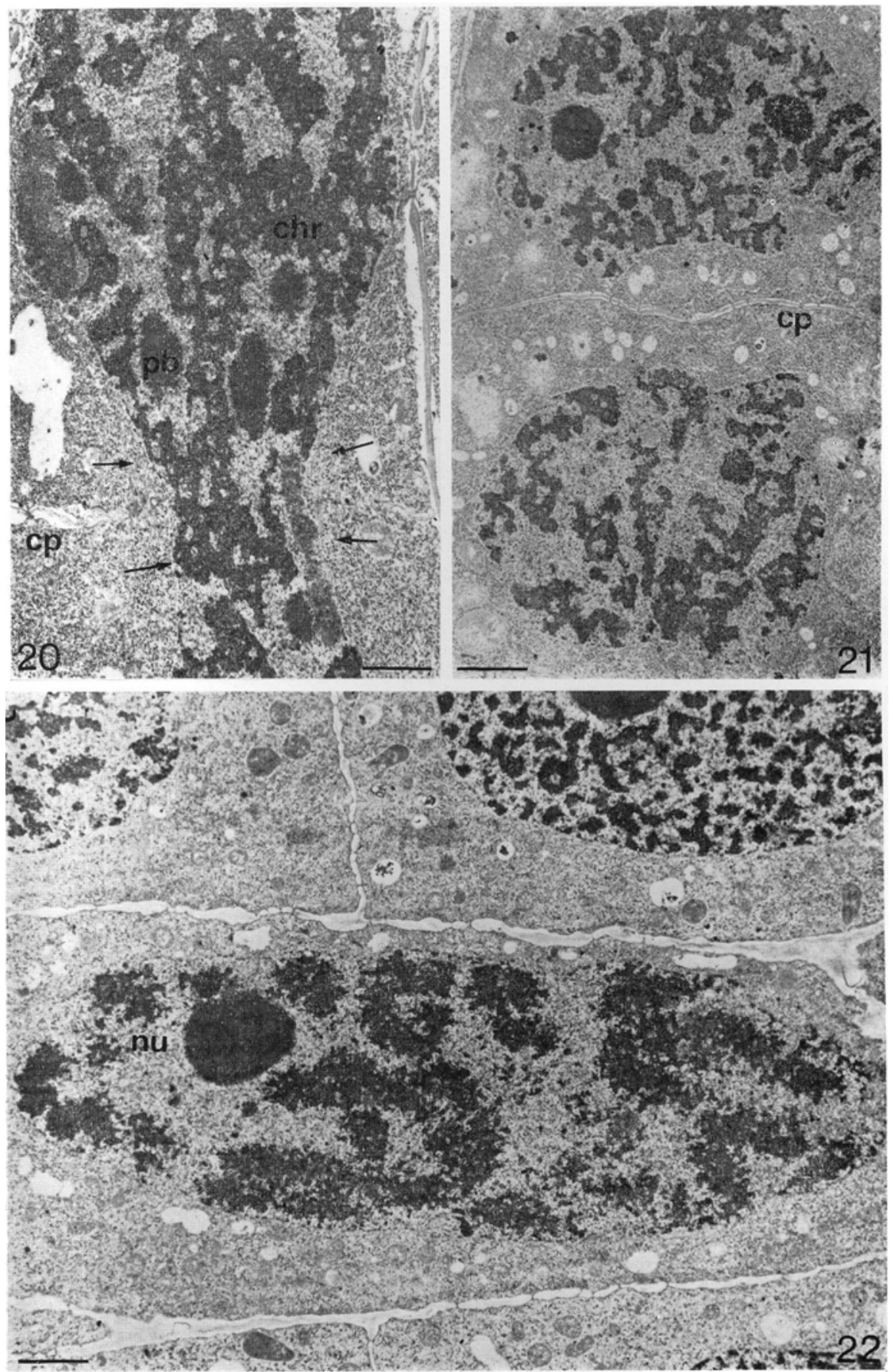
If the connections are considered as remnants of interphase chromatin fibres associated with the envelope so their failure to condense would not have allowed them to incorporate into the condensed chromosome.

\section{b) Nuclear envelope and microtubules.}

Our studies under the electron microscope confirm the necessity noted by other authors (HARRIS and DURE 1974) of a certain RNA during prophase for the disorganization of the nuclear envelope to take place. This RNA synthesis is probably related with simultaneous nucleolar RNA synthesis because under $\alpha$-amanitine treatment it proceeds as in control cells (MORENO Diaz De La Espina and Risueño 1976). If the treatment occurs after anaphase, when the nucleolus is still not active, mitoses go on as in controls (RISUEÑo et al. 1976).

In the case of EB treatment, there are ruptures in some points of this envelope, but its disorganization does not occur. The ruptures appear to be due to the chromosomes' movement. Nevertheless, in the light of these results, one may ask whether the nuclear envelope is broken by the action of the microtubules penetrating into it or, whether, once the nuclear envelope is broken at some points, the microtubules then polimerize.

Furthermore, the effect of each drug on the formation of microtubules is different; in the case of EB neither the formation of interzonal microtubules nor the formation of centromeric fibres is hindered while the formation of the mitotic spindle would be impeded by the presence of the nuclear envelope.

In the case of 3'AdR prophasic microtubules appear in a scarce number, but neither centromeric fibres nor interzonal microtubules do, in agreement with KIHLMan and OdMark (1966) opinion. Moreover, the effect is different with both drugs according to whether the treatment takes place during late $\mathrm{G}_{2}$ and prophase or behind metaphase, since, in the latter case, the formation of microtubules and the development of mitosis takes place as in controls (RISUEÑo et al. 1976).

Thus we can conclude two points: a) the trigger for microtubule polymerization during mitosis for both centromeric fibres and interzonal microtubules occurs before metaphase; b) This trigger is affected by 3'AdR, but not by other RNA synthesis inhibitors (EB and $\alpha$-amanitine).

Fig. 23. - 3' AdR $12 \mathrm{~h}$. Late prophase. The nucleolus has disappeared as an organized structure. The chromosomes show a greater condensation, and connections may be observed between themselves and with the nuclear envelope. Microtubules around the nucleus (arrows). x 16.199. Fig. 24. - 3' AdR $12 \mathrm{~h}$. Prometaphase. The chromosomes condensation is higher than in controls, and they begin to take a U-shape. Connections between the chromosomes and with the nuclear envelope (arrows). x 13.000 . 

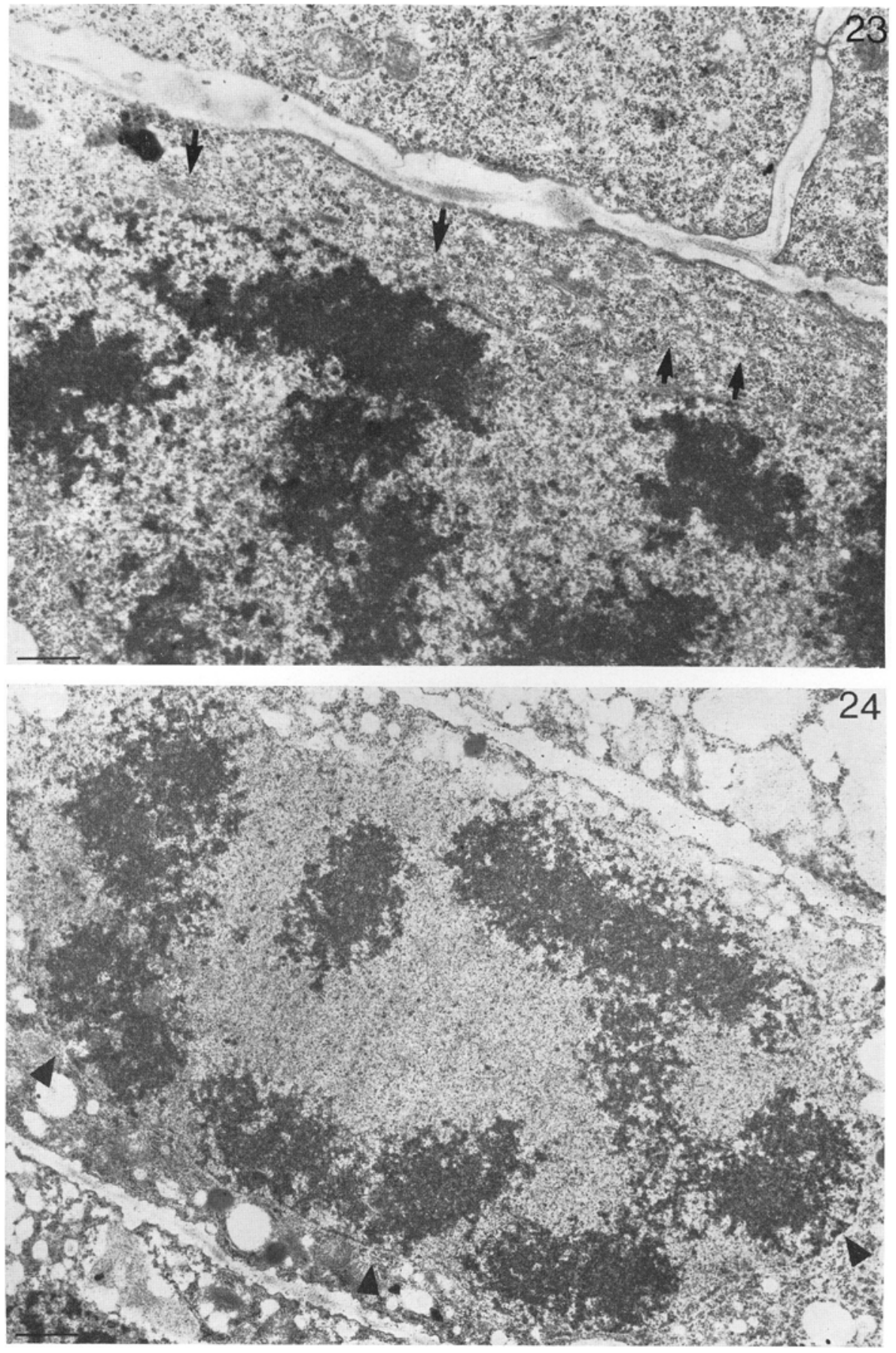

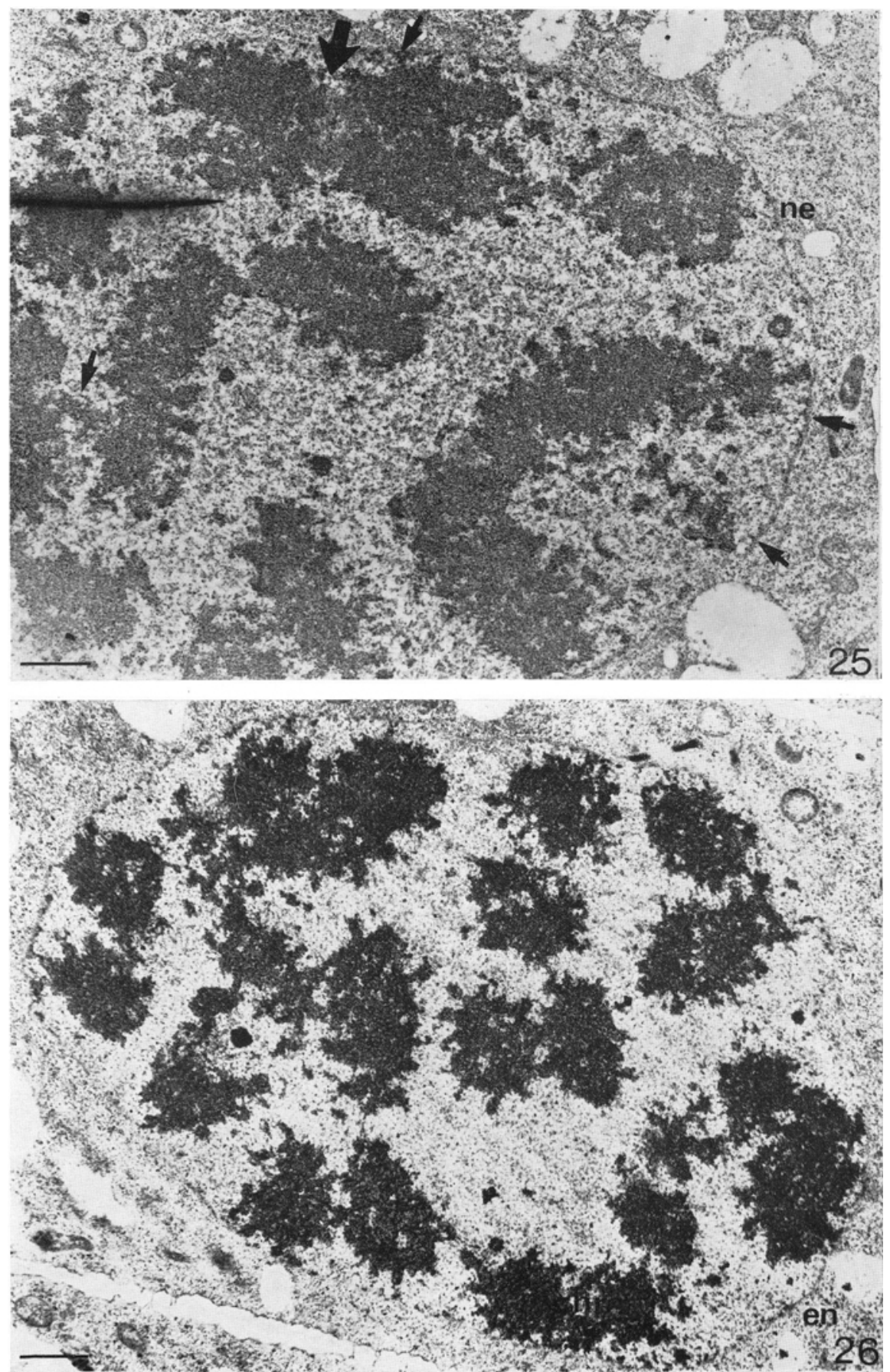
$E B$
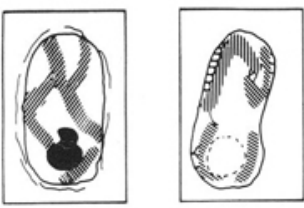

2

1
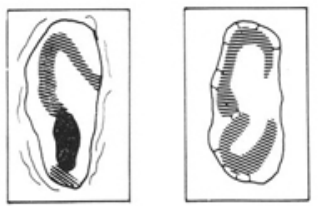

2

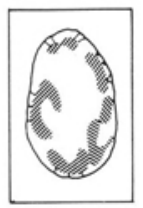

3

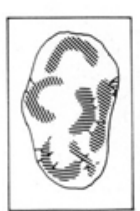

3

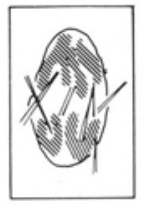

4

\section{3'Adr}

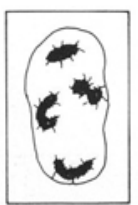

4

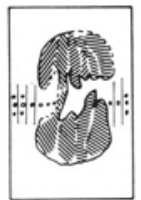

5

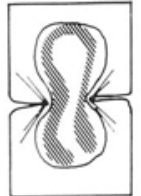

6

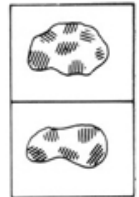

7

Fig. 27. - Evolution of mitosis under the effect of EB or 3' AdR; EB: 1) Prophase with chromatin condensation and nucleolus dispersion, microtubules are observed around the nuclear envelope at this stage. 2) Prometaphase: the nucleolus has completely dispersed and the chromosomes show connections between themselves and with the nuclear envelope 3) Metaphase. Chromosomes apposed to the nuclear envelope and connected with it. 4) Anaphase: the movement of the chromosomes towards the poles starts, and microtubules are observed attached to the kinetochores through the ruptures in the nuclear envelope. 5) Telophase: with chromosome decondensation, nuclear envelope reconstitution and formation of the cell plate. 6) Early interphase. The chromosome decondensation go on and the cell plate strangulates the nucleus. 7) Late interphase with decondensed chromatin.

3'AdR: 1) Phophase, microtubules are observed at this stage. 2) Prometaphase with no nucleolus at this stage and with connections between the chromosomes themselves and with the nuclear envelope 3) Metaphase with very condensed chromosomes 4) The end of the chromosome's change showing a very high contrast. $\equiv$ chromatin, nucleolus, o Golgi's vesicles.

In short, it seems to exist a certain RNA synthesized in the cell in the late $G_{2}$ - prophase period, which is responsible for the nuclear envelope disorganization at the end of prophase. This RNA is probably related with the biosynthetic nucleolar activity because it is inhibited by 3'AdR and EB, knowns nucleolar transcription inhibitors, but not by $\alpha$-amanitine, a powerful inhibitor of extranucleolar transcription.

The structural alterations induced in the chromosomes would not be due to the inhibition of this RNA, but a consequence of secondary effects of each drug on the chromatin condensation.

Fig. 25. - 3' AdR 12 h. Metaphase. The nuclear envelope still patent (ne). The chromosomes show both chromatids and the centromere region (big arrows). Chromosomal interconnections and connections with the nuclear envelope (arrows) may be observed. $x 10.735$.

Fig. 26. - 3' AdR $24 \mathrm{~h}$. A more advanced stage. The chromosomes (chr) reache its highest condensation at this stage and they are shorter than either in controls or EB treated cells. The chromosomal connections are very dense to the electrons. The nuclear envelope still patent (ne). $\mathrm{x} 8.300$. 
Before metaphase each drug have different effect on the formation of microtubules: in the case of $\mathrm{EB}$, neither the polymerization nor the function are blocked, but only the formation of a mitotic spindle, because the nuclear envelope does not disorganize. Nevertheless the 3'AdR causes an inhibition on the formation of mitotic microtubules either centromeric or interzonal fibres.

Acknowledgements. - We wish to thank Dr. A. M. LAMBERT and Dr. A. BAjER for their valuable comments and discussions on this work. The skillful technical assistance of Miss M. CARRASCOSA and E. Blanco is acknowledged. This work has been partially supported by the III Plan de Desarrollo of Spain and by a grant of the Rodríguez-Pascual Foundation.

\section{REFERENCES}

BEADlE G. W., 1932. - A gene for sticky chromosomes in Zea mays. Z. indukt. Abstamm. u. Vererb. L., 63: 195.217.

BIER K., 1957. - Endomitose und polytänie in den Naturzellkernen von Calliphora erythrocephala Meigen. Chromosoma, 8: 492-522.

Crawford L. V. and WARING M. J., 1967. - Supercoiling of Polyoma virus DNA measured by its interaction with etbidium bromide. J. Mol. Biol., 25: 23-30.

D'Aмato F., 1964. - Endopolyploidy as a factor in plant tissue development. Caryologia, 17: 41-52.

Garcia-Herdugo G., Fernandez-Gomez M. E., Hidalgo J. and Lopez-Saez J. F., 1974. - Effects of protein syntbesis inbibition during plant mitosis. Exptl. Cell Res., 89: 336-342.

Gextler L., 1953. - Endomitose und endomitotische Polyploydisierung. Protoplasmatologia, VI/C, Springer.

Gimenez-Martin G., Gonzalez-Fernandez A., De La Torre C. and Fernandez-Gomez M. E., 1971. - Partial Initiation on Endomitotic by 3'deoxyadeosine. Chromosoma, 33: 361-371.

Gimenez-Martin G., Risueño M. C., Fernandez-Gomez M. E. and Ahmadian P., 1973. Effect of Cordycepin on the fine structure of interpbase nuceoli in plant cells. Cytobiologie, 7: $181-192$.

Gonzalez-Fernandez A., Grmenez-Martin G. and Lopez-Saez J. F., 1970. - Effect produced by inbibitors of RNA synthesis on mitosis. Exptl. Cell Res., 60: 320-326.

Harris B., DURe III L. S., 1974. - Differential Effects of 3'Deoxynucleosides on RNA synthesis in Cotton Cotyledons. Biochemistry, 13: 5463-5467.

Ikeuchi T., SANBe M., Weinfeld H. and Sandberg A. A., 1971. - Induction of nuclear envelope around metaphase chromosomes after fusion with interphase. J. Cell Biol., 51: 104-115.

Kinlman B. A. and Odmark G., 1966. - Effects of adenine nucleosides on cbromosomes, cell division and nucleic acid synthesis in Vicia faba. Heredity, 56: 71-82.

LINDEgREN C. C., 1961. - The biological function of deoxyribonucleic acid. J. Theor. Biol., 1: 107-119.

Matsui S., Weinfeld H. and Sandererg A. A., 1971. - Dependence of cbromosome pulverization in virus-fused cells on events in the $G_{2}$ period. J. Natl. Cancer Inst., 47: 401-411.

McGill M., Pathak S. and Hsu T. C., 1974. - Effects of Ethidium Bromide on Mitotis and chromosomes: A possible material for Chromosome stickness. Chromosoma, 47: 157-167.

Moreno Diaz De la Espina S., Risueño M. C., Tandler C. J. and Fernandez-Gomez M. E., 1974. - Ultrastructure of the nucleolar cycle in plant cells: specific detection of nucleolar material and its fate in Mitosis. Eigth Intern. Congr. on Elect. Microscopy. Canberra, 2: 262-263.

Moreno Diaz De la Espina S., Risueño M. C., Fernandez-Gomez M. E. and Tandler C: J., 
1976. - Ultrastructure of the nucleolar cycle in meristematic cells of Allium cepa. J. de Microscopie et de Biol. Cell, 25: 265-278.

Moreno Diaz De La Espina S. and Risueño M. C., 1976. - Effect of $\alpha$-amanitine on the nucleolus of meristematic cells of Allium cepa interphase and mitosis: an ultrastructural analysis. Cytobiologie, 12: 175-188.

NAGL W., 1972. - Molecular and structural aspects of the endomitotic cbromosome cycle in Angiosperms. In: Chromosomes Today, 3: 17-23.

Nur U., 1968. - Endomitosis in the mealy bug Planococcus citri. Chromosoma, 24: 202-209.

PathaK J., McGill M. and Hsu T. C., 1975. - Actinomycin D effects on mitosis and chromosomes: sticky chromatids and localized lesions. Chromosoma, 50: 79-88.

Penman S., Rosbash M. and Penman M., 1970. - Messenger and Heterogeneous Nuclear RNA in HeLa Cells. Differential Inbibition by Cordycepin. Proc. of the Nat. Acad. Sci., 67: 1878-1885.

Rao P. N. and Johnson R. T., 1970. - Induction of cbromosome condensation in interphase cells. In: E. J. Dupraw. Advances in Cell and Molecular Biology Vol. 3, Academic Press, New York.

Risueño M. C., Gimenez-Martin G. and Gonzalez-Fernandez A., 1971. - Ultrastructural analysis of cytokinesis in plant cells blocked at prophase. J. Microscopie, 10: 331-336.

Risueño M. C., Moreno Diaz De La Espina S. and Gimenez-Martin G., 1975. - Effects de l'inbibition de la syntbése de l'ARN dans les cellules en mitose. J. Microscopie, 22: 33a.

Risueño M. C., Moreno Diaz De La Espina S., Gimenez-Martin G. and Fernandez-Gomez M. E., 1976. - Ultrastructure of the nucleolar material during plant mitosis in the presence of RNA synthesis inbibitors. J. de Microsc. et de Biol. Cell., 26: 5-8.

Risueño M. C., Fernandez-Gomez M. E., De La Torre C. and Gimenez-Martin G., 1972. Effect of Ethidium bromide on the fine structure of the nucleolus in plant cells. J. Ultrastructure Research, 39: 163-172.

De La Torre C., Risueño M. C. and Gimenez-Martin G., 1973. - Etbidium Bromide and its effects on the nuclear membrane cycle. Protoplasma, 76: 363-371.

Tschermak-Woess E., 1971. - Endomitose. In: Handb. Allg. Pathol. 2/II/1 569-625 Berl, Heidelb, N. Y. Springer Verlag.

Venable J. H. and Gogeshal K., 1965. - A simplified lead citrate stain for use in electron microscopy. J. Cell Biol., 25: 407-408.

WaRING M. J., 1965. - Drugs which affect the structure and function of DNA. Nature, 219: 1320-1324.

\section{SUMMARY}

The effect of RNA synthesis inhibition on the progress of mitosis was studied in meristematic cells of Allium cepa at the ultrastructural level. The continuous treatment with 3'AdR and EB on cells which are in the beginning of mitosis, causes the persistence of the nuclear envelope (Gonzalez-Fernandez et al. 1970) without blocking the chromosomal cycle (RIsUEÑo et al. 1975). In the case of EB there are ruptures in some points of the nuclear envelope but with 3'AdR it is still intact.

The ultrastructural analysis of 3'AdR treated cells shows a greater chromosomal condensation than in controls, and a structural modification of chromosomes, which acquire an $U$ form.

In the case of EB treatment the chromosomal condensation is similar to those in untreated cells. In both cases, the mitotic chromosomes show connections between each other and with the nuclear envelope. These connections are formed by chromosomal fibres, frameworked during the chromosomal condensation in prophase. Thus, the inhibition of RNA synthesis alters the chromosomal structure without affecting severely the chromosomal cycle.

The effect of each drug on the formation of microtubules is different: in the case of EB neither the formation of interzonal nor the formation of centromeric fibres is blocked. In the case of 3'AdR the formation of both types of microtubules is impeded. 